\title{
Is accurate and appropriate endoscope reprocessing too hard: an experience report
}

\section{Mini Review}

Upper and lower gastrointestinal endoscopy related healthcareassociated infections have been a challenge, especially after endoscopic retrograde cholangiopancreatography (ERCP) interventions. Despite the use of detergents and other disinfectants in the cleaning of endoscopes, microbiological cleaning of endoscopes is often a big problem. Microbiological monitoring of the endoscopes is performed with swabbing cultures or ATP-based measuring devices. The microbiological monitoring procedure should be defined in each setting checking each step of cleaning and disinfection. ATP-The ATPbioluminescence provides a fast and cost-effective microbiological monitoring for the endoscopes.

Upper and lower gastrointestinal endoscopy related healthcareassociated infections have been a challenge, especially after endoscopic retrograde cholangiopancreatography (ERCP) interventions. ${ }^{1}$ Although the detergents and other disinfectants are used in the cleaning of endoscopes, appropriate microbiological cleaning of endoscopes is often a big problem. ${ }^{2}$ Microbiological monitoring of the endoscopes is performed with swabbing cultures or ATP-based measuring devices. The frequency of microbiological monitoring varies from once a month to once every six months in different hospitals and countries. In this article, we aimed to share our experience about microbiological monitoring of endoscopes between 2014 and 2015. We validated reprocessing of 40 endoscopes used in the gastroenterology and general surgery endoscopy units. In both units, approximately 60 endoscopic interventions are performed in a day. A total of eight Automated Endoscope Reprocessors are used for cleansing. Each endoscope is disinfected with an enzymatic solution (Cidezyme, Johnson and Johnson Company, İstanbul, Turkey) for one minute and then a high-level disinfectant (Cidex OPA, Johnson and Johnson Company, İstanbul, Turkey) for five minutes after the intervention. ${ }^{3}$ In the microbiological evaluation, Stenotrophomonas maltophilia $(>100 \quad 000 \mathrm{cfu} / \mathrm{mL})$ was isolated from irrigation bottles. Extended-spectrum beta -lactamases and plasmid-mediated carbapenamase producing Klebsiella pneumonia and AmpC beta-lactamase producing Pseudomonas aeruginosa $(>100000 \mathrm{cfu} / \mathrm{mL})$ were isolated from elevator behind. AmpC betalactamase producing Pseudomonas aeruginosa $(>100 \quad 000 \mathrm{cfu} / \mathrm{mL})$ was isolated from gastroscope outer surface. Diphteroid bacilli $(>100$ $000 \mathrm{cfu} / \mathrm{mL})$ and methicillin-sensitive Staphylococcus aureus $(>100$ $000 \mathrm{cfu} / \mathrm{mL}$ ) were isolated from the endoscope hanger. After the extention of disinfection time to 10minutes and re-disinfection of all equipment before intervention in the morning, control cultures did not yield any microorganism. However, 140 endoscopes and 1200 cultures caused a remarkable workload and cost. We decided to use ATP-bioluminescence for microbiological monitoring of endoscopes. ATP-bioluminescence based tool yields result in 30 seconds, so the evaluation of endoscopes does not take a long time to keep them out of service. Decontamination procedure of endoscopes was defined and documented as:

i. The ATP-bioluminescence will be used in the microbiological monitoring of endoscopes every three months.
Volume 4 Issue 2 - 2017

\author{
Habip Gedik,' Leyla Günay,' Halil Alıs,, ${ }^{2}$ Aliye \\ Yüksel Soylu ${ }^{3}$ \\ 'Department of Infectious Diseases and Clinical Microbiology, \\ Ministry of Health Bakırköy Sadi Konuk Training and Research \\ Hospital,Turkey \\ ${ }^{2}$ Department of General Surgery, Ministry of Health Bakırköy \\ Sadi Konuk Training and Research Hospital, Turkey \\ ${ }^{3}$ Department of Gastroenterology, Ministry of Health Bakırköy \\ Sadi Konuk Training and Research Hospital,Turkey
}

Correspondence: Habip Gedik, Department of Infectious Diseases and Clinical Microbiology, Ministry of Health Bakırköy Sadi Konuk Training and Research Hospital, İstanbul,Turkey, Tel 009050533627 70, Email habipgedik@yahoo.com

Received: February 02, 2017 | Published: February 24, 2017

ii. Endoscopes should be disinfected in case they remain 12 hours of standby time after washing in the unit. Bottles and connecting hoses, which are used for endoscope irrigation should be cleaned and sterilized. In addition, sterile water must be used.

iii. Endoscopes with elevator wire channel may need to be washed using the syringe, due to the fact that flushing pressure may be insufficient.

iv. $\mathrm{pH}$ neutral and non-foaming detergents or enzymatic cleaners are recommended for cleaning. Enzymatic cleaners are recommended instead of $\mathrm{pH}$-unknown detergents.

v. The effective time of enzymatic cleaners should be defined by the manufacturer for manual and device usage.

vi. The $0.55 \%$ ortho-phthalaldehyde (OPA) is used for $5-12$ minutes in Europe, Latin America, and Asia; 5minutes in Canada, 10minutes in Australia, and 12minutes in the USA as a highlevel disinfection solution.

vii. Endoscope should be extended on a flat surface and aired with an injector into the air duct after taking from disinfector. High pressure that might damage the gun channel should be used only at the end portions. Also the inside and back of elevator should be dried with a sponge carefully.

viii. Elevator in duodenoscopy channel can be a problem, as brushing is not possible. The washing, enzymatic cleaning, drying must be performed by means of a syringe. After placing the disinfector connection hose into the elevator channel with a suitable adapter, and then disinfection, rinsing, and drying should be performed. Diameter of the channel is too small, so maximum 5 cc syringe should be used. ${ }^{4-7}$

The microbiological monitoring procedure should be defined in each setting checking each step of cleaning and disinfection. The ATPbioluminescence provides a fast and cost-effective microbiological monitoring for the endoscopes. 


\section{Acknowledgements}

None.

\section{Conflict of interest}

The author declares no conflict of interest.

\section{References}

1. Ayliffe GA. Nosocomial infections associated with endoscopy. In Mayhall CG, editor. Hospital Epidemiology and Infection Control. USA Williams \& Wilkins; 1996. p. 680-693.

2. Colt HG, Beamis JJF, James H Harrell JH, et al. Novel flexible bronchoscope and single-use disposable-sheath endoscope system-A preliminary technology evaluation. Chest. 2000;118(1):183-187.
3. Hernández A, Martró E, Puzo C, et al. In-use evaluation of Perasafe compared with Cidex in fiberoptic bronchoscope disinfection. $J$ Hosp Infect. 2003;54(1):46-51.

4. Nelson DB. Infection control during gastrointestinal endoscopy. $J$ Lab Clin Med. 2003;141:159-67.

5. Rutala WA. Selection and use of disinfectants in health care. In: Mayhall CG, editor. Hospital epidemiology and infection control. USA: Williams \& Wilkins; 1996. p. 913-936.

6. Rutala WA, Webe DJ. New Disinfection and Sterilization Method. Emerg Infect Dis. 2001;7(2):348-353.

7. Taşova Y. Endoskopi ile ilişkili hastane infeksiyonları. In: Doğanay M, Ünal S, editors. Turkey: Hastane İnfeksiyonları, Bilimsel Tıp Yayınevi; 2003. p. 797-819. 